\title{
Dear members of the Korean Cleft Palate-Craniofacial Association
}

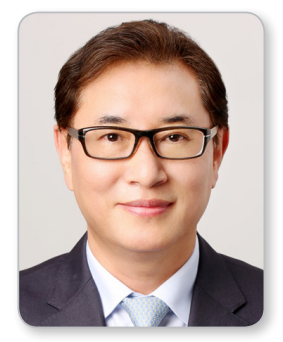

Myoung Soo Shin

Chairman of the General Assembly, the Korean Cleft Palate-Craniofacial Association
First of all, I would like to thank all our members for giving me this opportunity to serve the association. Our association, with its 27-year history, has developed into a reputable professional society with 1,201 members. Through your contributions and commitment, we have strengthened our global position, covering a variety of disciplines ranging from congenital malformations to cosmetic procedures.

The association, however, is now faced with new challenges, including ever-changing global and domestic circumstances, and the expansion of other professional disciplines into our traditional area of practice. We need to overcome these unprecedented hardships and challenges with a united front of all of our valued members, and to create a path for further growth and development into a more impactful professional society.

As I accept the role of the Chairman of the General Assembly of the Korean Cleft Palate-Craniofacial Association, I solemnly give you the following promise. I will strive to maintain the sta- tus of our society and the rights of each member by fostering amity and community between members. I will expand opportunities to share knowledge and advances by providing you with venues for academic communication. The executive board and I will make every effort to expand the society and to strengthen its position in the global academic community. In order to do so, we will need your full support and active participation more than ever. As our association moves forward, and we jointly carry our burdens and navigate future opportunities, I promise you that I will dedicate myself to creating such an environment.

As we close another year full of events and activities, we would like to express our sincere gratitude for your wholehearted support and cooperation. Our association is now embarking on another grand journey towards a glorious future. I wish you continued success and growth, as well as happiness, in the coming year 2020 . 